\title{
Autoavaliação do Conhecimento dos Profissionais de Contabilidade para a Adoção e a Aplicação dos Pronunciamentos Emitidos pelo Comitê de Pronunciamentos Contábeis ${ }^{1}$
}

\section{Self-Assessment of Knowledge of Professional Accounting for Adoption and Application of Pronouncements by Brazilian Accounting Pronouncements Committee}

\author{
Carlos Roberto Souza Carmo \\ Professor Assistente da Universidade Federal de Uberlândia-UFU \\ Universidade Federal de Uberlândia, Faculdade de Ciências Contábeis. \\ Endereço: Av. João Naves de Ávila, 2121 Bloco F - Sala 1F 215 \\ Santa Mônica, CEP: 38.400-902 - Uberlandia, MG - Brasil \\ e-mail: carlosjj2004@hotmail.com
}

\section{RESUMO}

O presente estudo buscou identificar como os profissionais contábeis do estado de Minas Gerais autoavaliam o seu conhecimento acerca do conteúdo e da aplicação dos pronunciamentos contábeis emitidos pelo Comitê de Pronunciamentos Contábeis (CPC). A partir da aplicação da análise fatorial exploratória foram identificados quatro fatores que agruparam os componentes principais relacionados ao nível de conhecimento dos 158 contadores integrantes da amostra dessa pesquisa, foram eles: os pronunciamentos que tratam de procedimentos aplicados a operações e atividades operacionais específicas; os pronunciamentos que contemplam procedimentos aplicados a grupos específicos dos componentes do Balanço e às novas demonstrações introduzidas pela convergência; os pronunciamentos que tratam das operações intercompanhias e das transações delas decorrentes; e, o grupo dos pronunciamentos que abordam os procedimentos referentes ao resultado, instrumentos financeiros e divulgação das demonstrações contábeis. Além de corroborar com os resultados de alguns estudos correlatos, essa investigação permitiu classificar aqueles quatro fatores/scores em ordem de crescente grandeza e compará-los com a frequência relativa observada, em cada um dos seus quartis, para cada um dos grupos de profissionais contábeis identificados nesse estudo, ou seja, contadores de empresas privadas, empresários contábeis com escritórios cadastrados no CRC-MG, profissionais contábeis sem escritório cadastrado no CRC-MG, funcionários públicos, auditores e/ou consultores independentes, docentes e/ou pesquisadores de Ciências Contábeis, e, outros não classificados em nenhum dos grupos anteriores, e, assim, em alguns casos, realizar algumas inferências sobre como a atuação profissional dos entrevistados poderia influenciar na sua busca por conhecimentos relacionados conteúdo e da aplicação dos pronunciamentos contábeis emitidos pelo CPC.

Palavras-chave: Conhecimento. Pronunciamentos contábeis. Análise fatorial exploratória.

\footnotetext{
${ }^{1}$ Artigo recebido em 07.10.2013. Revisado pelos pares em 11.11.2013 (blind review). Ajustado e Aceito para publicação em 20.11.2013. Recomendado para publicação por José Ribamar Marques de Carvalho (Editor Científico). Publicado em 12.12.2013. Organização responsável UACC/CCJS/UFCG.
} 


\section{ABSTRACT}

This study sought to identify how accounting professionals in the state of Minas Gerais self assess your knowledge about the content and application of accounting pronouncements issued by the Brazilian Accounting Pronouncements Committee (CPC). From the application of exploratory factor analysis, we identified four factors that grouped the main components related to the knowledge level of the 158 counters included in the sample of this research, they were: the pronouncements that address the operations and procedures applied specific operational activities, the statements which include procedures applied to specific groups of components swing and new statements introduced by convergence; pronouncements that treat intercompany transactions and transactions resulting there from, and the group of statements that address procedures regarding result, financial instruments and disclosure of financial statements. In addition to corroborate the results of some related studies, the analytical methodology used in this investigation allowed us to classify these four factors/scores in order of increasing magnitude and compare them with the observed relative frequency in each of the quartiles for each of the accounting professional groups identified in this study, in other words, counters private companies, business accounting with registered offices in CRC-MG, accounting professionals without a registered office in CRC-MG, public officials, auditors and/or independent consultants, teachers and/or Accounting researchers, and others not classified in any of the previous groups and thus, in some cases, make some inferences about the professional performance of the respondents could influence their search for knowledge related content and application of accounting pronouncements issued by CPC.

Keywords: Knowledge. Accounting pronouncements. Exploratory factor analysis.

\section{INTRODUÇÃO}

A Contabilidade enquanto ciência social sofre influência de fatores culturais, políticos e econômicos. Logo, sua evolução está diretamente relacionada à evolução das diversas sociedades ao longo do tempo.

Admitindo que as economias ao redor do mundo possuem práticas contábeis próprias, e, portanto, diferentes umas das outras, diante do fenômeno da globalização, a Ciência Contábil se deparou com um dos seus maiores desafios, ou seja, implementar a adoção de normas e procedimentos capazes de reduzir as diferenças da linguagem contábil entre as nações (RODRIGUES; NIYAMA, 2008; BARBOSA NETO; DIAS; PINHEIRO, 2009).

A fim de reduzir aquelas diferenças e tornar mais fácil a comunicação e a comparação das informações produzidas pela Contabilidade, instituiu-se o processo de convergência às normas internacionais de Contabilidade, que, segundo Villela (2007), busca a harmonização entre padrões contábeis internacionais e as práticas adotadas por cada país, sem perder de vista as suas particularidades.

No Brasil, esse processo foi iniciado já em 2005, por ocasião da criação do Comitê de Pronunciamentos Contábeis (CPC), cujas primeiras ações voltadas para a convergência estavam centradas na emissão de pronunciamentos a partir da utilização das normas internacionais criadas pelo International Accounting Standards Board (IASB) como base a partir das quais seriam realizados ajustes com vistas à sua adaptação à realidade brasileira, uma vez que o IASB passou a ser o órgão oficial de 
emissão de normas contábeis no âmbito mundial (MARTINS; MARTINS; MARTINS, 2007). Entretanto, o processo de convergência das normas brasileiras às normas internacionais só ganhou força a partir de 2008, quando a Lei no 11.638 (BRASIL, 2007) revogou alguns dos dispositivos contábeis da Lei $\mathrm{n}^{\circ} 6.404$ (BRASIL, 1976), vigente desde 1976.

Desde então, tem sido constante o incremento no volume de pesquisas sobre o fenômeno da convergência contábil brasileira às normais internacionais, por exemplo, os trabalhos de Klann et al. (2008), Barbosa Neto, Dias e Pinheiro (2009), Reis, Nogueira e Bim (2010), Shimamoto e Reis (2010), Guimarães et al. (2011), Oliveira et al. (2012), Viana e Sousa (2012), entre outros. Isso, segundo Villela (2007), traduz-se em evidências do interesse dos acadêmicos do Brasil pela temática e, ainda, é um bom indicador da sua relevância.

Ao levar em conta que a adoção das normas internacionais de Contabilidade passaram a ser obrigatórias a partir do exercício social de 2010 (ANTUNES et al., 2012), torna-se importante a realização de um estudo nessa área.

Nesse sentido, este estudo foi conduzido a partir do seguinte questionamento direcionador: como os profissionais contábeis do estado de Minas Gerais autoavaliam o seu conhecimento acerca do conteúdo e da aplicação dos pronunciamentos contábeis emitidos pelo Comitê de Pronunciamentos Contábeis brasileiro (CPC)?

Assim, objetiva analisar como os profissionais de Contabilidade do estado de Minas Gerais avaliam seu conhecimento para a adoção e a aplicação dos pronunciamentos contábeis emitidos pelo CPC.

O artigo que é composto por quatro outras seções além da presente introdução. Ou seja: inicialmente, foi constituída a plataforma teórica acerca da temática envolvendo a convergência das normas brasileiras de Contabilidade às normas internacionais, as possíveis dificuldades que poderiam ser impostas a este processo em função dos aspectos culturais inerentes à Contabilidade, e, ainda, apresentados alguns resultados de estudo correlatos a este, o que originou a seção dois; a seguir, foram identificados os procedimentos metodológicos referentes ao processo de coleta e análise dos dados necessários para responder ao questionamento direcionador da pesquisa científica, originando-se a seção três deste artigo; na sequência, procedeu-se à análise dos dados e à apresentação do conjunto de evidências coletadas a partir desta pesquisa, e, foi elaborada a seção quatro; finalmente, todo esse processo investigativo foi analisado e estabelecidas as considerações finais acerca dos seus resultados.

\section{FUNDAMENTAÇÃO TEÓRICA}

Iudícibus, Marion e Faria (2009) afirmam que a globalização dos mercados fez com que os profissionais de Contabilidade, entre outros, tivessem que se adaptar às 
mudanças introduzidas por aquele fenômeno, tanto em termos normatizadores e práticos quanto em conceitos e objetivos.

A convergência das normas brasileiras de Contabilidade às normas internacionais altera toda uma cultura de práticas profissionais, em sua grande parte, vigentes ao longo de mais de trinta anos, ou seja, desde a implementação da Lei ${ }^{\circ}$ 6.404 (BRASIL, 1976), em 1976, até a promulgação da Lei nº 11.638 (BRASIL, 2007), que passou a vigorar já em janeiro de 2008.

A despeito daquele mais de trinta de anos de cultura profissional contábil, percebe-se que as exigências de adequação por parte dos profissionais de Contabilidade, frente à convergência imposta pelo processo de globalização das economias mundiais, implicam na necessidade do profissional reconhecer as mudanças culturais enfrentadas e, ainda, na busca pelo conhecimento relativo às novas normas.

Ao considerar que o processo de convergência demanda a adaptação dos profissionais de contabilidade, o que por sua vez poderia gerar dificuldades àquele processo, Weffort (2005) afirma que o principal fator dessa dificuldade por estar relacionado aos aspectos culturais, pois, "a cultura integra-se às causas para a existência de diferenças contábeis, sendo capaz de influenciar nas normas e nas práticas" (WEFFORT, 2005, p. 138). Nessa mesma linha de raciocínio, Zeff (2007), ao enfatizar os obstáculos à convergência das normas contábeis, atribui aos aspectos culturais uma expressiva parcela de responsabilidade por um possível insucesso. Sendo que, dentre esses aspectos culturais, Zeff (2007) identifica a cultura de Contabilidade e a de Auditoria.

Gray (1988) analisou as influências culturais no desenvolvimento da Contabilidade e propôs uma classificação dessas influências de acordo com quatro valores contábeis: profissionalismo, uniformidade, conservadorismo e sigilo. $\mathrm{O}$ profissionalismo está relacionado à preferência de certas culturas profissionais e nacionais pelo julgamento profissional e pela autorregulação. A uniformidade está relacionada à disposição para se utilizar procedimentos contábeis mais rígidos em contraposição com países mais flexíveis, no que se refere às normas de Contabilidade. O conservadorismo refere-se à cautela na mensuração dos itens patrimoniais, em função à incerteza futura, em oposição a países mais propensos à flexibilização). O sigilo está relacionado com a preferência de certos países pela confidencialidade das informações contábeis em oposição a uma abordagem mais aberta e pública da Contabilidade.

Hofstede (1980) afirma que a prática reiterada de certos atos guia o modelo institucional e a prática. $\mathrm{O}$ autor ainda complementa explicando que cultura profissional é uma "programação mental" oriunda do ambiente em que os profissionais desenvolvem e adquirem suas experiências (HOFSTEDE, 1991, p. 46). Trompenaars e Hampden-Turner (1998), por sua vez, complementam ressaltando que a cultura profissional é um produto da interação entre as pessoas e, ainda, é um 
componente dessa interação. Logo, conforme já dito, as exigências de adequação por parte dos profissionais de Contabilidade, frente à convergência, implicam na necessidade dos contadores reconhecerem as mudanças culturais necessárias à sua atuação no mercado de trabalho que passou a demandar o conhecimento relativo às novas normas.

Acerca dos resultados de estudos relacionados às percepções dos profissionais envolvidos no processo de convergência das normas de Contabilidade, destaca-se inicialmente, o trabalho de Reis, Nogueira e Bim (2010), cujo objetivo foi identificar qual a percepção dos discentes e docentes de Ciências Contábeis, em relação ao processo de convergência às normas internacionais de Contabilidade. Para tanto, Reis, Nogueira e Bim (2010) realizaram um estudo com 158 discentes e 43 docentes, e, entre outros fatores, observaram que a maioria dos discentes tem conhecimento da existência do referido processo, contudo, eles acreditam que o mesmo está mais relacionado a questões formais, como a nomenclatura dos grupos patrimoniais, do que a aspectos conceituais. Entre os docentes, Reis, Nogueira e Bim (2010) observaram que, embora tenham conhecimento a respeito das mudanças, ainda apresentam certa resistência em promover as alterações conceituais necessárias ao ensino da Contabilidade sob a ótica das normas internacionais.

Shimamoto e Reis (2010) realizaram uma análise acerca da percepção dos profissionais contabilistas vinculados ao Sindicato dos Contabilistas de Londrina e ao Conselho Regional de Contabilidade do Paraná, sobre a convergência às normas internacionais. Eles constataram que a maioria absoluta dos pesquisados tem conhecimento da existência do referido processo. Contudo, tal percepção é de que o processo de convergência está mais relacionado a questões formais, como a nomenclatura dos grupos patrimoniais, do que a aspectos conceituais. Shimamoto e Reis (2010) também detectaram que, embora aqueles profissionais tenham conhecimento a respeito das mudanças, ainda apresentam certa resistência em promover as alterações necessárias nas suas rotinas profissionais.

Objetivando identificar a perspectiva do profissional contábil sobre a convergência das normas contábeis, e, ainda, analisar o nível de conhecimento desses profissionais sobre a matéria, as mudanças que poderiam ocorrer nos procedimentos da prática profissional e conhecer a aplicabilidade desse processo, Guimarães et al (2011) analisaram as respostas dos contadores de duas cidades do Estado do Espírito Santo, e, observaram que os profissionais contábeis participantes da pesquisa possuíam bom conhecimento teórico sobre a convergência Contábil, faltando-lhe conhecimento prático, uma vez que, a maioria desse profissionais ainda não havia aplicado o conteúdo relativo aos pronunciamentos contábeis propriamente ditos. Foi observado também que os profissionais pesquisados percebiam a importância do processo tanto para a sua atuação profissional quanto para a Ciência Contábil.

Por meio de uma pesquisa do tipo survey, Oliveira et al. (2012) analisaram as percepções dos contabilistas e docentes perante o processo de convergência da 
Contabilidade brasileira. A partir de uma amostra composta por 70 docentes e 45 contabilistas, Oliveira et al. (2012) concluiram que 66,7\% dos contabilistas e $70 \%$ dos docentes afirmaram que não se sentem capacitados para as mudanças decorrentes da adoção das normas do IASB, e, ainda, que as respostas dos docentes diferiram significativamente das opiniões dos contabilistas no tocante ao grau de importância atribuído ao processo de convergência.

Com o objetivo de avaliar a relação dos profissionais da área contábil credenciados pelo CRC na cidade do Natal em relação aos impactos da convergência contábil, Viana e Sousa (2012) entrevistaram 75 profissionais de forma individualizada e constataram despreparo e falta de perspectiva para adaptação aos novos padrões. Sendo que, segundo os pesquisados, a melhor forma de diminuir esse impacto é reavaliando as grades curriculares das instituições de ensino, para que elas tragam? mais disciplinas voltadas para essa temática.

Ao levar em conta que um processo como esse (a convergência) requer mudanças na cultura e nas práticas de toda uma classe profissional, observa-se a demanda por um posicionamento ativo tanto daqueles profissionais da área acadêmica quanto dos trabalhadores atuantes diretamente nesse mercado profissional.

\section{PROCEDIMENTOS METODOLÓGICOS}

Para coleta de dados, foi elaborado um questionário composto por questões fechadas e abertas, dividido em duas partes distintas. Na primeira parte, existiam questões de múltipla escolha (fechadas) em que foram solicitadas aos respondentes informações relativas à sua área de atuação profissional, tipo de empresa em que atuava, cargo, os respectivos níveis de conhecimento acerca das IFRS, e, entre outras informações de caráter geral. Também procurou identificar qual era a autoavaliação que do respondente acerca das suas necessidades de conhecimento relacionado às IFRS.

Na segunda parte do instrumento de coleta, foi apresentado aos respondentes a relação dos pronunciamentos emitidos pelo CPC (do CPC 01 ao 41, inclusive o CPC PME), identificados pelo seu número e título, e, ainda, foi solicitado ao respondente que desse uma nota de zero a dez para cada pronunciamento, de forma que tal nota refletisse o seu grau conhecimento sobre o conteúdo e a aplicação de cada um daqueles pronunciamentos, sendo, zero para nenhum conhecimento e dez para conhecimento total.

Após a elaboração do instrumento de coleta, foi realizado um pré-teste com cinco profissionais contábeis e cinco docentes do curso de Ciências Contábeis, sendo que, após analisarem o referido instrumento, apresentaram suas considerações, o que permitiu que o mesmo fosse ajustado segundo a percepção daqueles profissionais. 
Após isso, o instrumento de coleta foi hospedado na plataforma Google Drive ( (antigo Docs $®)$, ao longo dos meses setembro, outubro e novembro de 2012. Para contatar os profissionais respondentes, foram enviadas mensagens (via e-mail) a todos os contadores regularmente registrados no Conselho Regional de Contabilidade do Estado de Minas Gerais (CRC-MG), Brasil, no início de cada um dos meses em questão. E, em meados de dezembro, foi formada a base de dados com respostas de 171 profissionais, que passaram a compor a amostra dessa pesquisa.

Ao levar em conta que as informações relativas ao nível de conhecimento sobre cada um dos 41 pronunciamentos abordados nessa investigação proporcionaria um conjunto de estatísticas univariadas relacionadas, por exemplo, à média, desvio padrão, coeficiente de variação de Pearson, entre outros, cuja interpretação seria prejudicada, pela natureza de cada uma das variáveis (pronunciamentos), e, ainda, pelo fato de que análise de correlação supostamente não permitiria traçar um perfil acerca do objeto dessa investigação. Dessa forma, optou-se pela análise fatorial exploratória para identificação dos componentes principais (fatores) do conjunto de dados. Visto que esta técnica multivariada tem por objetivo identificar as dependências internas de um conjunto de variáveis muito grande, a partir dos relacionamentos existentes em um número menor de características latentes, que neste caso, são denominados de fatores. Para tanto, foi utilizado o pacote estatístico para as ciências sociais SPSS (Statistical Package for the Social Sciences) versão 15.0, para extração dos componentes principais (fatores).

Com o objetivo de maximizar a interpretação dos fatores encontrados pela análise fatorial inicial, foi realizada a rotação ortogonal pelo método Varimax, cuja ideia consiste em rotacionar os fatores de forma a provocar o aparecimento de altas cargas para poucas variáveis (COOLEY; LOHNES, 1971). Ou seja, a rotação pelo método Varimax faz com que os pesos dos fatores pesquisados sejam melhores distribuídos e isso, por sua vez, melhora o poder explicativo de cada fator identificado a partir do processo de análise fatorial (FÁVERO et al, 2009).

Além da elaboração de estatísticas descritivas, dentre elas a análise de frequência relativa, após a aplicação da análise fatorial rotacionada pelo método Varimax, foram realizados os testes KMO (Kaiser-Meyer-Olkin) para análise da adequação da amostra (FIELD, 2009), o teste de Bartlett para avaliar a possibilidade das variáveis observadas não serem correlacionadas (FIELD, 2009), e, ainda, o Alpha de Cronbach para avaliar o nível de confiabilidade tanto dos fatores detectados quanto da segunda parte do instrumento de coleta (FIELD, 2009). Cabe destacar que todos esses procedimentos de análise foram realizados considerando a plataforma teórica constituída para realização desta investigação.

Diante do exposto, esta pesquisa pode ser caracterizada como um estudo exploratório de natureza qualitativa, apoiado em métodos quantitativos aplicados (FACHIN, 2001; MARTINS, 2000). 


\section{APRESENTAÇÃO E DISCUSSÃO DOS RESULTADOS}

Para facilitar a análise e validação dos dados, e, ainda, a interpretação das evidências identificadas a partir dos fatores pesquisados neste trabalho, esta seção foi dividida em duas partes. A primeira aborda os aspectos estatísticos provenientes do processo de análise multivariada. A segunda trata da interpretação dos resultados a partir do produto final da análise fatorial, à luz da problematização proposta e da plataforma teórica constituída para suportar esse processo investigativo.

\subsection{Análise dos Dados e sua Validação}

Apesar de coletadas informações de diversas naturezas, nessa investigação serão abordados somente os aspectos relativos à autoavaliação dos profissionais de Contabilidade mineiros acerca do seu conhecimento sobre conteúdo e da aplicação dos pronunciamentos contábeis emitidos pelo CPC, conforme problematização proposta inicialmente.

Nesse sentido, com relação à atuação profissional daqueles 171 respondentes integrantes da amostra, foi observado que a maioria dos profissionais pesquisados está exercendo a profissão contábil na condição de empregado de empresas privadas, conforme demonstrado pelos dados resumidos na Tabela1.

Tabela 1 - Área de atuação profissional dos integrantes da amostra de pesquisa

\begin{tabular}{lcc}
\hline Descrição & Frequência & observada \\
\cline { 2 - 3 } & Absoluta & Relativa \\
\hline Contador de empresa privada (empregado) & 63 & $36,8 \%$ \\
\hline Empresário contábil com escritório cadastrado no CRC & 34 & $19,9 \%$ \\
\hline Profissional contábil sem escritório cadastrado no CRC & 17 & $9,9 \%$ \\
\hline Funcionário público & 9 & $5,3 \%$ \\
\hline Auditor/Consultor independente & 10 & $5,8 \%$ \\
\hline Docente/Pesquisador de Ciências Contábeis & 15 & $8,8 \%$ \\
\hline Outro & 23 & $13,5 \%$ \\
\hline Total & $\mathbf{1 7 1}$ & $\mathbf{1 0 0 , 0} \%$ \\
\hline
\end{tabular}

Fonte: elaborado com base nos dados da pesquisa, a partir de análises no SPSS.

Acerca da tipologia relacionada às empresas em que os integrantes da amostra de pesquisa atuam, foi observada uma maior frequência nas empresas limitadas, conforme demonstrado pelos dados resumidos na Tabela 2. Contudo, também pode ser destacado que as empresas prestadoras de serviços contábeis, auditoria e consultoria contábil também apresentaram uma frequência bem expressiva em relação às demais, apesar de inferior às empresas limitadas. 
Tabela 2 - Perfil das empresas em que atuam os integrantes da amostra de pesquisa

\begin{tabular}{lcc}
\hline Descrição & Frequência & observada \\
\cline { 2 - 3 } & Absoluta & Relativa \\
\hline Companhia aberta & 19 & $11,1 \%$ \\
\hline Companhia fechada & 16 & $9,4 \%$ \\
\hline Empresa limitada & 55 & $32,2 \%$ \\
\hline Governo (municipal, estadual e federal) & 14 & $8,2 \%$ \\
\hline Terceiro setor & 9 & $5,3 \%$ \\
\hline Instituições de ensino e treinamento & 14 & $8,2 \%$ \\
\hline Prestadora de serviços contábeis/auditoria/consultoria & 44 & $25,7 \%$ \\
\hline Total & $\mathbf{1 7 1}$ & $\mathbf{1 0 0 , 0} \%$ \\
\hline
\end{tabular}

Fonte: elaborado com base nos dados da pesquisa, a partir de análises no SPSS.

Neste ponto cabe destacar que foi dada atenção às informações relativas ao tipo de atuação profissional e às empresas em que os integrantes da amostra de pesquisa atuam, pois, presumiu-se que essas informações, além de direcionarem as práticas e vivências dos profissionais contábeis no seu dia a dia, também, podem ser direcionadoras das demandas por conhecimentos relacionados às normas contábeis avaliadas nessa investigação, conforme será demonstrado mais adiante na seção 4.2 deste trabalho.

Ao analisar as informações gerais acerca da autoavaliação dos profissionais contábeis mineiros sobre seus conhecimentos relacionados às IFRS, foi observado que todos reconhecem ter necessidade de adquirirem tais conhecimentos, e, a grande maioria $(48,5 \%)$ informou ter necessidade de conhecimentos avançados, conforme pode ser visto na Tabela 3.

Tabela 3 - Autoavaliação acerca das necessidades de conhecimento relacionado às IFRS

\begin{tabular}{lcc}
\hline Descrição & \multicolumn{2}{c}{ Frequência observada } \\
\cline { 2 - 3 } & Absoluta & Relativa \\
\hline Demanda conhecimentos integrais, pois, não conhece nada sobre IFRS & 29 & $17,0 \%$ \\
\hline Demanda conhecimentos básicos & 25 & $14,6 \%$ \\
\hline Demanda conhecimentos intermediários & 34 & $19,9 \%$ \\
\hline Demanda conhecimentos avançados & 83 & $48,5 \%$ \\
\hline Total & $\mathbf{1 7 1}$ & $\mathbf{1 0 0 , 0} \%$ \\
\hline
\end{tabular}

Fonte: elaborado com base nos dados da pesquisa, a partir de análises no SPSS.

Antes de iniciar a análise fatorial propriamente dita, foi avaliada a consistência interna do instrumento de coleta, no que se refere à sua segunda parte, portanto, aquela em que os profissionais atribuíram notas indicando o seu grau de conhecimento sobre dos pronunciamentos do CPC. O instrumento em questão apresentou um Alpha de Cronbach de 0,988, o que permitiu concluir ele pode ser considerado altamente confiável, uma vez que são desejáveis valores acima de 0,70 (FIELD, 2009). 
Além de avaliar a confiabilidade da escala envolvendo as notas atribuídas ao nível de conhecimentos dos contadores mineiros sobre os pronunciamentos do CPC, ainda no processo de tratamento do banco de dados para realização da análise fatorial, por meio da padronização das notas atribuídas aos pronunciamentos mediante o cálculo dos respectivos "Z scores", com a ajuda da análise do gráfico de Boxplot foram identificadas e excluídas as observações relativas a 13 outliers, o que reduziu a amostra inicial, de 171, para 158 observações válidas para aplicação da análise fatorial exploratória.

Em seguida, foi avaliada a adequação da amostra para aplicação do método de análise multivariada escolhido para esse estudo. Para tanto, foi realizado o teste de KMO (Kaiser-Meyer-Olkin), cujo valor foi de 0,959, o que permite afirmar que a amostra dessa pesquisa pode ser considerada ótima segundo Field (2009) e Hutcheson e Sofroniou (1999), uma vez que, esse teste indica a proporção da variância dos dados que pode ser atribuída aos fatores identificados a partir da análise fatorial, sendo que, quanto mais próximo de um mais adequada é a amostra à aplicação da análise fatorial.

Ainda no processo de validação da amostra de pesquisa, foi aplicado o teste de Bartlett, cuja significância do seu valor parâmetro foi 0,00, portanto, menor que 0,05 , o que permite concluir que as observações relativas às notas atribuídas pelos respondentes da pesquisa são correlacionadas entre si, permitindo-se, assim, que fosse iniciado a aplicação da análise fatorial (FÁVERO et al, 2009; FIELD, 2009).

O diagrama de declividade, apresentado na Figura 1, evidencia que seriam extraídos quatro fatores explicativos dos componentes principais relativos às notas atribuídas aos pronunciamentos técnicos. Ou seja, a análise do "ponto de inflexão", destacado na Figura 1, sinaliza que a partir do fator 4, a variância explicada cai de forma muito pequena não justificando a extração de um número maior de fatores explicativos dos componentes principais em análise nessa pesquisa. 


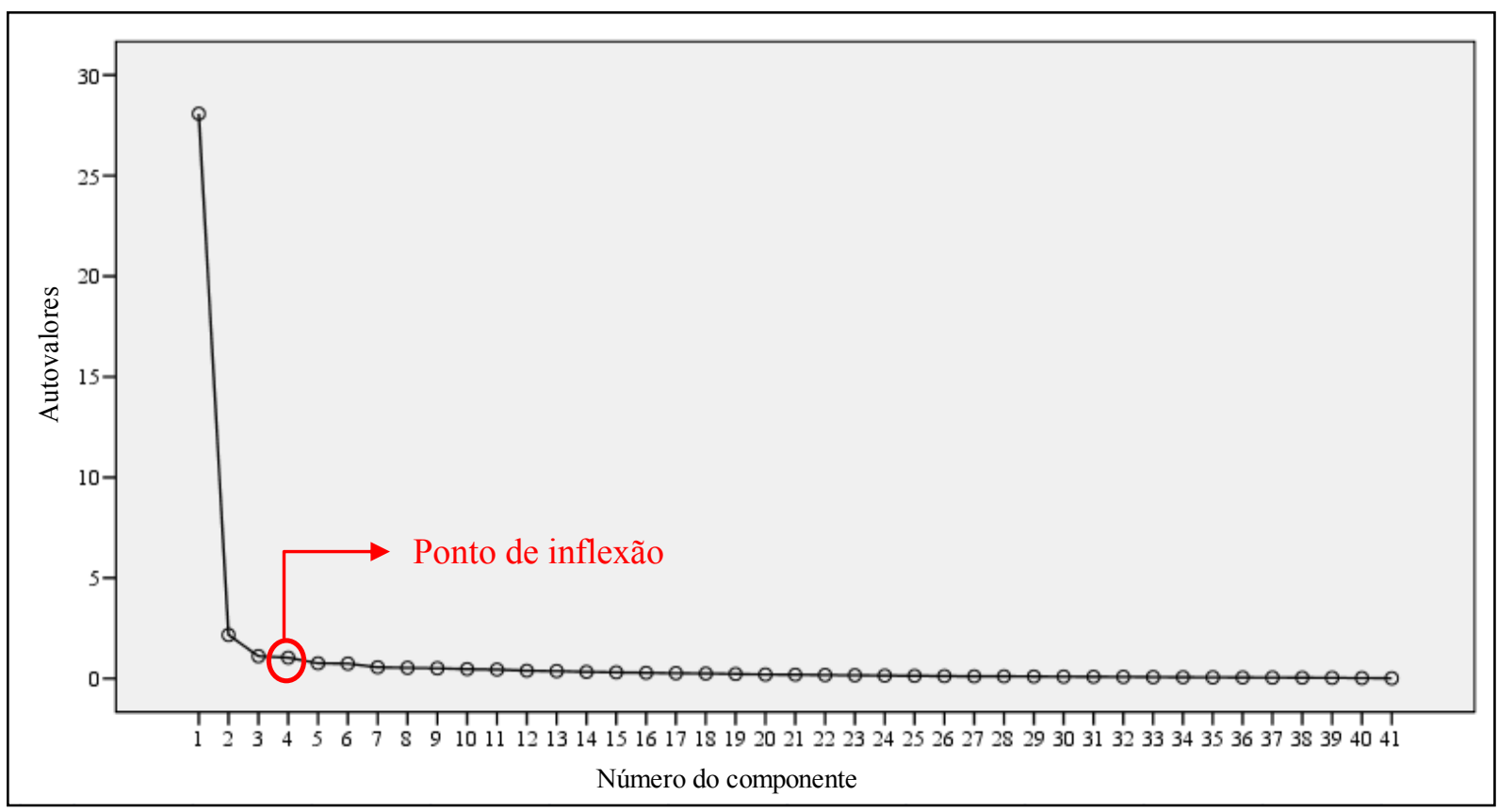

Figura 1 - Diagrama de declividade (Scree plot)

Fonte: elaborado com base nos dados da pesquisa, a partir de análises no SPSS.

A partir das informações geradas pelo SPSS, pôde-se observar que aqueles quatro fatores identificados foram capazes de explicar uma variância de 79,03\% das 158 observações realizadas. Contudo, nessa etapa, foi constatado que o primeiro fator sozinho explicava $68,48 \%$ da variância, e, os outros três juntos explicariam apenas 10,55\%, conforme pode ser observado na Figura 1. Diante do exposto, procedeu-se à rotação pelo método Varimax de forma a fazer com que os pesos dos três últimos fatores pesquisados fossem melhores distribuídos, o que geraria uma melhora o poder explicativo de cada fator identificado, conforme sugere Fávero et al (2009).

Após rotacionar os fatores pelo método Varimax, aqueles quatro fatores identificados continuaram a apresentar uma variância total explicada de 79,03\%, contudo, a distribuição desse poder explicativo para cada fator passou a ser melhor distribuída, ou seja, 23,31\% para o fator 1,21,89\% para o fator $2,16,92 \%$ para o fator 3 , e, 16,91\% fator 4 , conforme pode ser observado na parte de baixo da Tabela 4 .

Com relação à interpretação da variância explicada, pode-se afirmar que, em conjunto, os fatores pesquisados explicam 79,03\% da variação observada nos dados originais, sendo que, essa mesma análise se aplica aos fatores individuais, contudo, respeitando aqueles percentuais próprios de cada fator (FÁVERO et al, 2009; FIELD, 2009). Nesse sentido, pode-se inferir que, daquele conjunto de variáveis formado pelas notas atribuídas por cada um dos 171 entrevistados aos pronunciamentos analisados neste estudo (do CPC 01 ao 41, e ainda, o CPC das MPE), foram identificados apenas quatro fatores com características latentes (semelhantes) em relação à percepção desses entrevistados acerca da sua autoavaliação para os 
respectivos graus de conhecimento acerca do conteúdo e da aplicação daqueles pronunciamentos contábeis.

Tabela 4 - Análise Fatoriala para análise dos componentes principais

\begin{tabular}{|c|c|c|c|c|c|}
\hline & \multicolumn{4}{|c|}{ Componentes } & \multirow{2}{*}{$\begin{array}{c}\text { Comunalidades }^{b} \\
c\end{array}$} \\
\hline & Fator 1 & Fator 2 & Fator 3 & Fator 4 & \\
\hline CPC_10 & 0,836 & & & & 0,86 \\
\hline CPC_08 & 0,787 & & & & 0,79 \\
\hline CPC_11 & 0,745 & & & & 0,76 \\
\hline CPC_17 & 0,725 & & & & 0,80 \\
\hline CPC_07 & 0,709 & & & & 0,70 \\
\hline CPC_02 & 0,701 & & & & 0,80 \\
\hline CPC_22 & 0,691 & & & & 0,85 \\
\hline CPC_21 & 0,645 & & & & 0,81 \\
\hline CPC_29 & 0,585 & & 0,522 & & 0,72 \\
\hline CPC_05 & 0,556 & & & & 0,69 \\
\hline CPC_43 & 0,520 & & & & 0,73 \\
\hline CPC_PME & & & & & 0,65 \\
\hline CPC_01 & & 0,785 & & & 0,83 \\
\hline CPC_13 & & 0,782 & & & 0,82 \\
\hline CPC_04 & & 0,703 & & & 0,75 \\
\hline CPC_06 & & 0,686 & & & 0,71 \\
\hline CPC_03 & & 0,669 & & & 0,80 \\
\hline CPC_12 & & 0,642 & & & 0,80 \\
\hline CPC_09 & & 0,634 & & & 0,71 \\
\hline CPC_27 & & 0,625 & & 0,549 & 0,87 \\
\hline CPC_37 & & 0,604 & & 0,519 & 0,79 \\
\hline CPC_26 & & 0,594 & & 0,575 & 0,83 \\
\hline CPC_25 & & 0,584 & 0,513 & & 0,82 \\
\hline CPC_16 & & 0,541 & & & 0,78 \\
\hline CPC_28 & & & 0,734 & & 0,87 \\
\hline CPC_15 & & & 0,633 & & 0,81 \\
\hline CPC_19 & & & 0,621 & & 0,81 \\
\hline CPC_20 & & & 0,586 & & 0,73 \\
\hline CPC_24 & & & 0,572 & & 0,78 \\
\hline CPC_18 & & & 0,550 & & 0,77 \\
\hline CPC_23 & & & 0,532 & & 0,74 \\
\hline CPC_31 & & & 0,517 & & 0,75 \\
\hline CPC_40 & & & 0,510 & 0,505 & 0,88 \\
\hline CPC_32 & & & & 0,719 & 0,80 \\
\hline CPC_30 & & & & 0,691 & 0,87 \\
\hline CPC_33 & 0,593 & & & 0,671 & 0,86 \\
\hline CPC_36 & & & & 0,624 & 0,83 \\
\hline CPC_35 & & & & 0,580 & 0,80 \\
\hline CPC_38 & & & & 0,546 & 0,82 \\
\hline CPC_39 & 0,506 & & & 0,510 & 0,86 \\
\hline CPC_41 & & & & & 0,78 \\
\hline
\end{tabular}




\begin{tabular}{lcccc}
\hline Alfa de Cronbach & 0,964 & 0,970 & 0,961 & 0,968 \\
\hline \% de Var. Explicada & 23,310 & 21,889 & 16,924 & 16,905 \\
\hline \% Acumulado & 23,31029 & 45,19933 & 62,1229 & 79,02806 \\
\hline
\end{tabular}

(a) Método de rotação: Varimax com normalização Kaiser. A rotação convergiu em 10 iterações.

(b) Comunalidades reproduzidas a partir do modelo identificado. Média para o Fator 1=0,76. Média para o Fator 2=0,79. Média para o Fator 3=0,78. Média para o Fator 4=0,83.

(c) Resíduos são calculados pela diferença entre as correlações observadas e as correlações reproduzidas. Existem 77 observações para resíduos não redundantes, portanto, com valores absolutos superiores a 0,05 . Isso equivale a $9,0 \%$ dos resíduos gerados pelo modelo pesquisado a partir da análise fatorial. Segundo Field (2009), o valor máximo desejável para esses resíduos é de até $50 \%$.

Fonte: elaborado com base nos dados da pesquisa, a partir de análises no SPSS.

Ainda com base nas informações contidas na Tabela 4, mais especificamente, na parte inferior dela, o Alpha de Cronbach calculado individualmente para cada um dos fatores pesquisados apresentou valores acima de 0,90, que permite inferir que todos eles podem ser considerados confiáveis (FIELD, 2009). Adicionalmente, na última coluna da Tabela 4, foram apresentadas as comunalidades para cada um dos pronunciamentos que integraram os quatro fatores pesquisados. Essa informação diz respeito à variância explicada por cada um dos pronunciamentos técnicos após a rotação Varimax, sendo que, o desejável seria que esses valores fossem superiores a 0,70, considerando a extração de 4 fatores (FIELD, 2009). Assim, ao comparar as Comunalidades reproduzidas a partir do modelo identificado, de acordo com seu agrupamento dos pronunciamentos em fatores, foram observadas médias sempre superiores a 0,70 para cada fator, conforme informação complementar " $b$ " destacada ao final da Tabela 4, e, isso por sua vez, reforça a confiabilidade acerca dos fatores identificados, no que diz respeito ao agrupamento das notas atribuídas por cada um dos 171 entrevistados aos mais de 40 pronunciamentos analisados neste estudo.

Finalizando o processo de análise dos dados e a respectiva validação, resta observar que na parte central da Tabela 4, sob a denominação de "Componentes", desdobrada em colunas com a identificação dos fatores, encontram-se as somas rotacionadas das cargas fatoriais ao quadrado de cada pronunciamento, em relação ao respectivo fator. Em outras palavras, essa é a contribuição de cada pronunciamento para a composição de cada um dos quatro fatores pesquisados a partir da análise fatorial, após a rotação Varimax para otimização da variância explicada. Essa informação permite identificar qual variável (pronunciamento do CPC) foi agrupada em cada fator.

\subsection{Interpretação dos Resultados Identificados com Base na Análise Fatorial}

A partir dos resultados da análise fatorial, foram identificados quatro fatores que agrupavam os componentes principais relacionados à autoavaliação dos 
contadores mineiros, integrantes da amostra dessa pesquisa, acerca dos seus conhecimentos sobre os pronunciamentos contábeis do CPC, conforme demonstrado por ordem de grandeza de cargas fatoriais, na Tabela 4.

O Fator 1 agrupou os pronunciamentos CPC 02, CPC 05, CPC 07, CPC 08, CPC 10, CPC 11, CPC 17, CPC 22, CPC 21, CPC 29, СРC 43 e CPC PME, sendo que, esse último não apresentou carga fatorial identificada na Tabela 4, pois, foi solicitado ao SPSS que omitisse as cargas inferiores a 0,40. Devido à natureza geral daqueles pronunciamentos técnicos, o Fator 1 foi denominado de fator explicativo da autoavaliação dos conhecimentos relacionados aos "Procedimentos aplicados à operações e à atividades operacionais específicas".

O Fator 2 agrupou os pronunciamentos CPC 01, CPC 03, CPC 04, CPC 06, CPC 09, CPC 12, CPC 13, CPC 16, CPC 25, CPC 26, СPC 27 e CPC 37, sendo que, alguns desses pronunciamentos também contribuíram com cargas para os fatores $3 \mathrm{e}$ 4, contudo, além dessa contribuição ter apresentando uma carga fatorial menor, no processo de análise foi levado em consideração a natureza de cada pronunciamento para o seu agrupamento. Devido àquela natureza, o Fator 2 foi denominado de fator explicativo da autoavaliação dos conhecimentos relacionados aos "Procedimentos aplicados a grupos específicos dos componentes do Balanço e às novas demonstrações introduzidas".

O Fator 3 agrupou os pronunciamentos CPC 15, CPC 18, CPC 19, CPC 20, CPC 23, CPC 24, CPC 28, CPC 31. Devido natureza de cada pronunciamento para o seu agrupamento, esse fator foi denominado de fator explicativo da autoavaliação dos conhecimentos relacionados às "Operações intercompanhias e as transações delas decorrentes".

O Fator 4 agrupou os pronunciamentos CPC 30, CPC 32, CPC 33, CPC 35, CPC 36, СРC 38, CPC 39, CPC 40, CPC 41. Aqui cabe observar que o CPC 41 não apresentou carga fatorial identificada na Tabela 4, pois, conforme já dito, foi solicitado ao SPSS que omitisse as cargas inferiores a 0,40, contudo, ele integrou o Fator 4. Adicionalmente, observa-se que o CPC 40 também contribui com carga para o Fator 3, contudo, considerando a sua natureza e a pequena diferença entre aquelas cargas, ele foi vinculado ao Fator 4 . Nesse sentido, ao considerar a natureza daqueles pronunciamentos e as maiores cargas fatoriais, o Fator 4 foi denominado de fator explicativo da autoavaliação dos conhecimentos relacionados ao "Resultado, Instrumentos Financeiros e Divulgação das Demonstrações Contábeis".

Com relação ao agrupamento dos pronunciamentos do CPC naqueles quatro fatores e àquelas denominações atribuídas de acordo com suas naturezas, cabe observar que tais denominações não encontraram respaldo nos resultados de estudos anteriores analisados neste estudo, e, principalmente, elas foram identificadas a partir de algumas similaridades relacionadas à interpretação acerca da aplicabilidade de cada pronunciamento agrupado naqueles quatro fatores. 
A partir das informações geradas pelo SPSS, procedeu-se a classificação dos scores atribuídos para cada fator em ordem crescente. Em função desse procedimento pôde-se observar menores valores em relação aos pronunciamentos relativos às "Operações intercompanhias e transações delas decorrentes" (Fator 3), o que pode ser interpretado como uma a maior falta de conhecimento acerca dos pronunciamentos agrupados naquele fator. Em segundo lugar, foi observada a falta de conhecimento em relação aos pronunciamentos referentes aos "Procedimentos aplicados à operações e atividades operacionais específicas" (Fator 1). Em terceiro lugar, foram identificados os pronunciamentos que abordam assuntos relacionados ao "Resultado, Instrumentos Financeiros e Divulgação das Demonstrações Contábeis" (Fator 4). Em quarto lugar, portanto, com menores problemas relacionados ao nível de conhecimento dos entrevistados, foram identificados os "Procedimentos aplicados a grupos específicos dos componentes do Balanço e as novas demonstrações introduzidas" (Fator 2).

Ao classificar todos os fatores em ordem de crescente grandeza e compará-los com a frequência relativa observada em cada quartil, de forma a cruzar as informações referentes à atuação profissional e os níveis de conhecimentos referentes aos "Procedimentos aplicados às operações e atividades operacionais específicas" (Fator 1), foi constatado que $44 \%$ dos "Auditores e Consultores independentes" integrantes da amostra de pesquisa tiveram seus scores classificados no $1^{\circ}$ Quartil, conforme pode ser constatado pelas informações resumidas na Tabela 5.

Tabela 5 - Análise da frequência relativa observada no Fator 1, em relação à atuação profissional

\begin{tabular}{lccccc}
\hline Descrição & $\begin{array}{c}\mathbf{1}^{\mathbf{0}} \\
\text { Quartil }\end{array}$ & $\begin{array}{c}\mathbf{2}^{\mathbf{0}} \\
\text { Quartil }\end{array}$ & $\begin{array}{c}\mathbf{3}^{\mathbf{0}} \\
\text { Quartil }\end{array}$ & $\begin{array}{c}\mathbf{4}^{\mathbf{0}} \\
\text { Quartil }\end{array}$ & Total \\
\hline Contador de empresa privada (empregado) & $18 \%$ & $30 \%$ & $25 \%$ & $27 \%$ & $100 \%$ \\
\hline Empresário contáb. com escrit. cadast. no CRC & $28 \%$ & $22 \%$ & $19 \%$ & $31 \%$ & $100 \%$ \\
\hline Profissional contáb. sem escrit. Cadast. no CRC & $27 \%$ & $40 \%$ & $13 \%$ & $20 \%$ & $100 \%$ \\
\hline Funcionário público & $25 \%$ & $13 \%$ & $38 \%$ & $25 \%$ & $100 \%$ \\
\hline Auditor/Consultor independente & $44 \%$ & $22 \%$ & $11 \%$ & $22 \%$ & $100 \%$ \\
\hline Docente/Pesquisador de Ciências Contábeis & $33 \%$ & $8 \%$ & $33 \%$ & $25 \%$ & $100 \%$ \\
\hline Outro & $27 \%$ & $23 \%$ & $32 \%$ & $18 \%$ & $100 \%$ \\
\hline
\end{tabular}

Fonte: elaborado com base nos dados da pesquisa, a partir de análises no SPSS.

Essa evidência pode ser um indício de que os Auditores e Consultores que integraram a amostra dessa pesquisa estejam muito mais propensos a adquirir conhecimentos relacionados a "procedimentos aplicados a grupos específicos dos componentes do Balanço e as novas demonstrações introduzidas", a "operações intercompanhias e transações delas decorrentes" e conhecimentos relacionados aos pronunciamentos que abordam o "resultado, instrumentos financeiros e divulgação das demonstrações contábeis", o que parece ser coerente, se considerado que eles atendem a empresas com variados tipos de atividades profissionais. 
Aliás, aqueles indícios, apontados no parágrafo anterior, ganham mais força ainda quando analisadas as frequências relativas contidas nas Tabelas 6, 7 e 8, onde, os Auditores e Consultores que integraram a amostra dessa pesquisa tiveram mais de $65 \%$ das suas frequências relativas situadas no $3^{\circ}$ e no $4^{\circ}$ Quartil, dos outros três grupos de pronunciamentos do CPC, que são aqueles com maiores scores atribuídos aos níveis de conhecimentos apontados pelos profissionais que compuseram a amostra da pesquisa.

Na autoavaliação dos scores atribuídos aos "Procedimentos aplicados a grupos específicos dos componentes do Balanço e as novas demonstrações introduzidas", verificou-se uma maior frequência relativa para os scores classificados no $1^{\mathrm{o}}$ quartil por parte dos "Profissionais contábeis sem escritório cadastrado no CRC", conforme pode ser constatado nas informações resumidas na Tabela 6.

Tabela 6 - Análise da frequência relativa observada no Fator 2, em relação à atuação profissional

\begin{tabular}{lccccc}
\hline Descrição & $\begin{array}{c}\mathbf{1}^{\mathbf{0}} \\
\text { Quartil }\end{array}$ & $\begin{array}{c}\mathbf{2}^{\mathbf{0}} \\
\text { Quartil }\end{array}$ & $\begin{array}{c}\mathbf{3}^{\mathbf{0}} \\
\text { Quartil }\end{array}$ & $\begin{array}{c}\mathbf{4}^{\mathbf{0}} \\
\text { Quartil }\end{array}$ & Total \\
\hline Contador de empresa privada (empregado) & $30 \%$ & $22 \%$ & $15 \%$ & $33 \%$ & $100 \%$ \\
\hline Empresário contáb. com escrit. cadast. no CRC & $19 \%$ & $47 \%$ & $19 \%$ & $16 \%$ & $100 \%$ \\
\hline Profissional contáb. sem escrit. Cadast. no CRC & $47 \%$ & $13 \%$ & $13 \%$ & $27 \%$ & $100 \%$ \\
\hline Funcionário público & $38 \%$ & $25 \%$ & $25 \%$ & $13 \%$ & $100 \%$ \\
\hline Auditor/Consultor independente & $11 \%$ & $11 \%$ & $44 \%$ & $33 \%$ & $100 \%$ \\
\hline Docente/Pesquisador de Ciências Contábeis & $17 \%$ & $0 \%$ & $42 \%$ & $42 \%$ & $100 \%$ \\
\hline Outro & $14 \%$ & $32 \%$ & $45 \%$ & $9 \%$ & $100 \%$ \\
\hline
\end{tabular}

Fonte: elaborado com base nos dados da pesquisa, a partir de análises no SPSS.

Essa evidência pode ser um indício de que esses profissionais (contadores sem escritório cadastrado no CRC), por trabalharem com variedade muito grande clientes/empresas, identificaram que seus níveis de conhecimentos de uma maneira geral precisam ser aprimorados, pois, em cerca de $60 \%$ das frequências relativas para os scores atribuídos a esses profissionais ficaram situados no $1^{\underline{o}}$ e no $2^{\underline{o}}$ Quartil de todos os fatores, conforme pode ser constatado a partir de análises nas informações contidas nas Tabelas 5, 6, 7 e 8 .

Já em relação aos conhecimentos relacionados às "Operações intercompanhias e transações delas decorrentes" (Fator 3), foi observada uma maior frequência relativa para os profissionais atuantes como "Empresários contábeis com escritórios cadastrados no CRC" em relação aos scores classificados no $1^{\circ}$ Quartil, conforme demonstrado na Tabela 7. Essa evidência pode ser um indício de que, pela natureza e variedade de empresas-clientes destes escritórios, os "Empresários contábeis com escritórios cadastrados no CRC" estejam mais atentos aos procedimentos técnicos relacionados àquele grupo de pronunciamentos agrupados no Fator 3. 
Tabela 7 - Análise da frequência relativa observada no Fator 3, em relação à atuação profissional

\begin{tabular}{lccccc}
\hline Descrição & $\begin{array}{c}\mathbf{1}^{\mathbf{0}} \\
\text { Quartil }\end{array}$ & $\begin{array}{c}\mathbf{2}^{\mathbf{0}} \\
\text { Quartil }\end{array}$ & $\begin{array}{c}\mathbf{3}^{\mathbf{0}} \\
\text { Quartil }\end{array}$ & $\begin{array}{c}\mathbf{4}^{\mathbf{0}} \\
\text { Quartil }\end{array}$ & Total \\
\hline Contador de empresa privada (empregado) & $25 \%$ & $28 \%$ & $38 \%$ & $8 \%$ & $100 \%$ \\
\hline Empresário contáb. com escrit. cadast. no CRC & $34 \%$ & $25 \%$ & $19 \%$ & $22 \%$ & $100 \%$ \\
\hline Profissional contáb. sem escrit. Cadast. no CRC & $27 \%$ & $47 \%$ & $7 \%$ & $20 \%$ & $100 \%$ \\
\hline Funcionário público & $25 \%$ & $25 \%$ & $13 \%$ & $38 \%$ & $100 \%$ \\
\hline Auditor/Consultor independente & $11 \%$ & $11 \%$ & $22 \%$ & $56 \%$ & $100 \%$ \\
\hline Docente/Pesquisador de Ciências Contábeis & $8 \%$ & $8 \%$ & $0 \%$ & $83 \%$ & $100 \%$ \\
\hline Outro & $27 \%$ & $18 \%$ & $23 \%$ & $32 \%$ & $100 \%$ \\
\hline
\end{tabular}

Fonte: elaborado com base nos dados da pesquisa, a partir de análises no SPSS.

Em relação aos conhecimentos relacionados aos conhecimentos referentes ao "Resultado, Instrumentos Financeiros e Divulgação das Demonstrações Contábeis", foi observada uma maior frequência relativa para os profissionais "Contadores de empresa privada (empregado)" (Fator 4) em relação aos scores classificados no $1^{\text {o }}$ Quartil, seguidos de perto pelos "Profissionais contábeis sem escritório cadastrado no CRC", conforme demonstrado na Tabela 8.

Tabela 8 - Análise da frequência relativa observada no Fator 4, em relação à atuação profissional

\begin{tabular}{lccccc}
\hline Descrição & $\begin{array}{c}\mathbf{1}^{\mathbf{0}} \\
\text { Quartil }\end{array}$ & $\begin{array}{c}\mathbf{2}^{\mathbf{0}} \\
\text { Quartil }\end{array}$ & $\begin{array}{c}\mathbf{3}^{\mathbf{0}} \\
\mathbf{Q u a r t i l}^{-}\end{array}$ & $\begin{array}{c}\mathbf{4}^{\mathbf{0}} \\
\text { Quartil }\end{array}$ & Total \\
\hline Contador de empresa privada (empregado) & $35 \%$ & $30 \%$ & $20 \%$ & $15 \%$ & $100 \%$ \\
\hline Empresário contáb. com escrit. cadast. no CRC & $13 \%$ & $31 \%$ & $22 \%$ & $34 \%$ & $100 \%$ \\
\hline Profissional contáb. sem escrit. Cadast. no CRC & $33 \%$ & $13 \%$ & $27 \%$ & $27 \%$ & $100 \%$ \\
\hline Funcionário público & $13 \%$ & $25 \%$ & $25 \%$ & $38 \%$ & $100 \%$ \\
\hline Auditor/Consultor independente & $22 \%$ & $11 \%$ & $33 \%$ & $33 \%$ & $100 \%$ \\
\hline Docente/Pesquisador de Ciências Contábeis & $25 \%$ & $8 \%$ & $17 \%$ & $50 \%$ & $100 \%$ \\
\hline Outro & $18 \%$ & $27 \%$ & $36 \%$ & $18 \%$ & $100 \%$ \\
\hline
\end{tabular}

Fonte: elaborado com base nos dados da pesquisa, a partir de análises no SPSS.

Em relação aos "contadores empregados de empresas privadas", aos "empresários contábeis com escritórios cadastrados no CRC" e aos "funcionários públicos", todos integrantes da amostra dessa pesquisa, as frequências relativas observadas para os scores atribuídos àqueles quatro grupos de conhecimentos alternaram-se entre $40 \%$ e $60 \%$, ora no $1^{\circ}$ e $2^{\circ}$ Quartil, ora no $3^{\circ}$ e $4^{\circ}$ Quartil, de maneira que não foi possível identificar uma tendência específica para esses grupos de profissionais.

Em relação aos 15 docentes e pesquisadores da área de Ciências Contábeis que responderam à pesquisa, foi constatado que suas frequências relativas observadas para os scores atribuídos àqueles quatro grupos de conhecimentos estiveram sempre com sua maioria localizando-se no $3^{\underline{0}}$ e $4^{\circ}$ Quartil das Tabelas 5, 6, 7 e 8, o que indica que eles se autoavaliaram com maiores níveis de conhecimentos, com base nos fatores calculados a partir da análise fatorial. 


\section{CONSIDERAÇÕES FINAIS}

Ao admitir que a convergência das normas contábeis brasileiras às normas internacionais é um processo inevitável e que, por isso, implica em mudanças na cultura e nas práticas de Contabilidade dos contadores brasileiros, esta pesquisa buscou identificar como os profissionais contábeis do estado de Minas Gerais autoavaliam o seu conhecimento acerca do conteúdo e da aplicação dos pronunciamentos contábeis emitidos pelo CPC.

A partir da aplicação da análise fatorial, foram identificados quatro grupos de conhecimentos relacionados àqueles pronunciamentos, e, assim, foi possível analisar como os profissionais mineiros se posicionam diante dos conhecimentos demandados pelo processo de convergência, mediante o conhecimento e a aplicação do conteúdo dos pronunciamentos do CPC.

Inicialmente, foi identificado que a autoavaliação profissionais contábeis do estado de Minas Gerais acerca do seu conhecimento sobre o conteúdo e a aplicação dos pronunciamentos contábeis emitidos pelo CPC pode ser classificada em quatro grupos distintos de pronunciamentos, ou seja: pronunciamentos relacionados a procedimentos aplicados às operações e à atividades operacionais específicas; pronunciamentos relacionados aos procedimentos aplicados a grupos específicos dos componentes do Balanço e às novas demonstrações introduzidas; pronunciamento técnicos que abordam operações intercompanhias e as transações delas decorrentes; e, pronunciamentos relacionados ao resultado, a instrumentos financeiros e à divulgação das demonstrações contábeis.

Ao classificar os scores atribuídos à cada um daqueles quatro fatores em ordem crescente, foi observado que os pronunciamentos relacionados às operações intercompanhias e transações delas decorrentes foi o que indicou uma autoavaliação caracterizada pela maior falta de conhecimento acerca dos pronunciamentos agrupados naquele fator. Em segundo lugar, foi observada a falta de conhecimento em relação aos pronunciamentos referentes aos procedimentos aplicados a operações e atividades operacionais específicas. Em terceiro lugar, foram identificados os pronunciamentos que abordam assuntos relacionados ao resultado, instrumentos financeiros e divulgação das demonstrações contábeis. Em quarto lugar, portanto, com menores problemas relacionados ao nível de conhecimento dos entrevistados, foram identificados os pronunciamentos técnicos referentes aos procedimentos aplicados a grupos específicos dos componentes do balanço e as novas demonstrações introduzidas.

Acerca de um maior nível de conhecimento sobre os pronunciamentos técnicos referentes aos procedimentos aplicados a grupos específicos dos componentes do balanço e as novas demonstrações introduzidas, poder-se-ia inferir que, em função do produto final da contabilidade consistir na elaboração e 
apresentação das demonstrações contábeis, os profissionais entrevistados estariam mais preocupados com os pronunciamentos relacionados a este assunto. Contudo, tal inferência não pôde ser confirmada a partir dos resultados dos estudos anteriores pesquisados para constituição da plataforma teórica deste estudo.

A despeito de outras evidências discutidas na seção 4.2, os resultados desse estudo corroboram parcialmente com a diferença de conhecimentos entre contabilistas e docentes identificada nos estudos de Oliveira et al. (2012). Contudo, deve ser levado em conta que esta pesquisa foi direcionada aos profissionais vinculados ao CRC-MG, e, assim, os 18 docentes respondentes não caracterizaram-se como o foco central desse estudo.

Apesar das metodologias analíticas utilizadas nos estudos de Shimamoto e Reis (2010) e Guimarães et al (2011) serem diferentes daquela utilizada nesta investigação, de certa forma, seus achados puderam ser confirmados, pois, tanto naqueles trabalhos quanto neste, foi observada a existência de certo níveis de conhecimento acerca do processo de convergência e das demandas profissionais requeridas por ele.

Apesar das contribuições prestadas por esta investigação, destaca-se com principal limitação o fato da amostra ter sido composta por um número muito pequeno de respondentes, se comparada a todo universo formado pelos contadores com registro do CRC de Minas Gerais.

A despeito dessa e de outras limitações que não foram destacadas, espera-se que os resultados dessa investigação possam ser somados aos resultados de outros estudos de natureza correlata e, assim, contribuir para o debate e a pesquisa, ambos relacionados ao processo de convergência das normas contábeis brasileiras de Contabilidade.

\section{REFERÊNCIAS}

ANTUNES, M. T. P. et al. A adoção no Brasil das normas internacionais de contabilidade IFRS: o processo e seus impactos na qualidade da informação contábil. Revista de Economia \& Relações Internacionais, v.10, n. 20, p. 5-10, jan./2012. Disponível em: http://www.faap.br/faculdades/economia/ciencias_economicas/pdf/revista_economia_20. pdf. Acesso em 19 nov. 2013.

BARBOSA NETO, J. E.; DIAS, W. de O.; PINHEIRO, L. E. T.. Impacto da convergência para as IFRS na análise financeira: um estudo em empresas brasileiras de capital aberto. Contabilidade Vista \& Revista, Belo Horizonte, v. 20, n. 4, p. 131-153, out.-dez./2009.

BRASIL. Lei n.o 6.404, de 15 de dezembro de 1976. Diário Oficial [da] República Federativa do Brasil, Poder Executivo, Brasília, DF, 17 dez.1 976, p. 1 (SUPLEMENTO). 
Disponível

em:

http://legislacao.planalto.gov.br/legisla/legislacao.nsf/b110756561cd26fd03256ff50061

2662/e3ec08d7c01679cb032569fa007417ce?OpenDocument. Acesso em 20 ago. 2013.

Lei n. ${ }^{\circ}$ 11.638, de 28 de dezembro de 2007. Diário Oficial [da] República Federativa do Brasil, Poder Executivo, Brasília, DF, 28 dez. 2007, p. 2 (EDIÇÃO EXTRA). Disponível em: http://legislacao.planalto.gov.br/legisla/legislacao.nsf/b110756561cd26fd03256ff50061 2662/d5eb4020ba175561832573c2003c106f?OpenDocument. Acesso em 20 ago. 2013.

COOLEY, W. W.; LOHNES, P. R. Multivariate data analysis. New York: John Wiley \& Sons, Inc. 1971.

FACHIN, O.. Fundamentos da metodologia. 3. ed. São Paulo: Saraiva, 2001.

FÁVERO, L. P. et al. Análise de dados: modelagem multivariada para tomada de decisões. Rio de Janeiro: Elsevier, 2009.

FIELD, A.. Descobrindo a estatística usando SPSS. 2. ed. Porto Alegre: Artmed, 2009.

GRAY, S. J. Towards a theory of cultural influence on the development of accounting systems internationally. Abacus, Scotland, v. 24, n. 01, p. 1-15, Mar./1988.

GUIMARÃES, L. M. et al. O profissional contábil diante da convergência das normas contábeis: análise da preparação desse profissional nos processos organizacionais. In: SIMPÓSIO DE EXCELÊNCIA EM GESTÃO E TECNOLOGIA, 8., 2011, Resende. Anais... Resende: AEDB, 2011.

HOFSTEDE, G.. Culture's consequences: international differences in work related values. Beverly Hills: Sage Publicações, 1980.

Culture and organizations: intercultural cooperation and its importance for survival. New York: McGraw-Hill, 1991.

HUTCHESON, G; SOFRONIOU, N.. The multivariate social scientist. London: Sage, 1999.

IUDÍCIBUS, S. de. MARION, J. C.. FARIA, A. C. de. Introdução à Teoria da Contabilidade. São Paulo: Atlas, 2009.

KLANN, R. C. et al. Impacto das diferenças entre as normas contábeis brasileiras e americanas nos indicadores de desempenho de empresas brasileiras participantes da governança corporativa. In: ENCONTRO DA ASSOCIAÇÃO NACIONAL DE PÓS- 
GRADUAÇÃO E PESQUISA EM ADMINISTRAÇÃO (EnANPAD), 32., 2008. Rio de Janeiro. Anais... Rio de Janeiro: EnANPAD, 2008.

MARTINS, G. de A.. Manual para elaboração de monografias e dissertações. 2. ed. São Paulo: Atlas, 2000.

MARTINS, E.; MARTINS, V. A.; MARTINS, E. A. Normatização contábil: ensaio sobre sua evolução e o papel do CPC. Revista de Informação Contábil (RIC/UFPE), Recife, v. 1, n. 1, p. 7-30, set./2007.

NIYAMA, J. K.; SILVA, C. A. T.. Teoria da Contabilidade. São Paulo: Atlas, 2008.

OLIVEIRA, M. do S. S. de et al. Convergência da Contabilidade brasileira aos padrões internacionais: um estudo comparativo entre contabilistas e docentes. In: CONGRESSO USP DE CONTROLADORIA E CONTABILIDADE, 9., 2012, São Paulo. Anais... São Paulo: USP, 2012.

REIS, L. G. dos; NOGUEIRA, D. R.; BIM, E. A.. Convergência às normas internacionais de Contabilidade: uma análise sob a perspectiva docente e discente. In: ECONTRO DA ANPAD, 34. 2010, Rio de Janeiro. Anais... Rio de Janeiro: ANPAD, 2010.

RODRIGUES, J. M. NIYAMA, J. K. Convergência internacional: uma análise comparativa entre os padrões contábeis da China e do IASB. In: CONGRESSO USP DE CONTROLADORIA E CONTABILIDADE, 8., 2008, São Paulo. Anais... São Paulo: USP, 2008.

SHIMAMOTO, L. S.; REIS, L. G. dos..Convergência às normas internacionais de Contabilidade: uma análise sob a perspectiva dos profissionais contabilistas. Revista de Estudo Contábeis, Londrina, v. 1, n. 1, p. 90-105, Jul./Dez. 2010.

TROMPENAARS, F.; HAMPDEN-TURNER, C.. Riding the waves of culture: understanding diversity in global business. 2.ed. New York: McGraw-Hill, 1998.

VIANA, S. C. P.; SOUSA, J. A.. A internacionalização das normas contábeis e a sua relação com os profissionais da área contábil credenciados pelo CRC na cidade do NatalRN. Revista Científica Connexio, Mossoró, ano 2, n. 1, p.65-78, ago./2012- jan./2013. Disponível em: www.aedb.br/seget/artigos11/34414349.pdf. Acesso em 21 ago. 2013.

VILLELA, M. V. E.. Uma reflexão sobre a necessidade de harmonização contábil mundial baseada em uma comparação entre as normas de business combination do IASB, do FASB e do Brasil. Revista Brasileira de Contabilidade, Brasília, n. 164, p.23-35, mar.abr./2007. 
WEFFORT, E. F. J.. O Brasil e a harmonização contábil internacional: influências dos sistemas jurídico e educacional, da cultura e do mercado. São Paulo: Atlas, 2005.

ZEFF, S. A. Some obstacles to global financial reporting comparability and convergence at a high level of quality. The British Accounting Review, Aston University (UK), v. 9, issue 4, p. 290-302, dec./2007. 


\section{APÊNDICE 1}

\section{Relação dos Pronunciamentos Técnicos Emitidos pelo Comitê de Pronunciamentos Contábeis (CPC) Avaliados nessa Investigação}

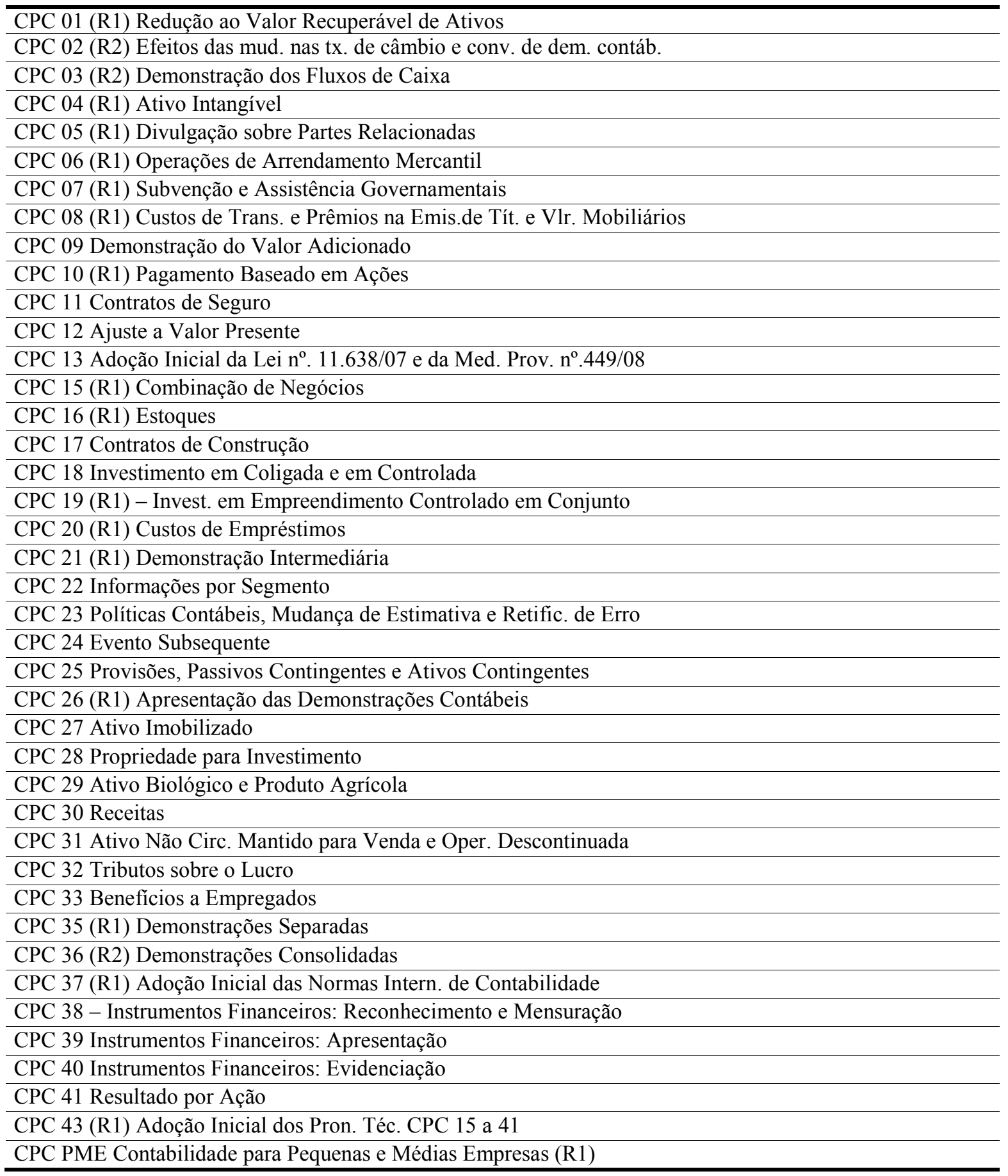




\section{APÊNDICE 2}

\section{Reprodução do Instrumento de Coleta Utilizado nessa Investigação}

\section{Apresentação}

O Brasil, aderindo à tendência mundial, começa a exigir a aplicação das Normas Internacionais de Contabilidade (Internacional Financial Reporting Standards - IFRS) nas empresas brasileiras a partir de 2010. Esse processo foi iniciado já em 2005, por ocasião da criação do Comitê de Pronunciamentos Contábeis (CPC), cujas primeiras ações voltadas para a convergência estavam centradas na emissão de pronunciamentos a partir do estudo e adequação das normas internacionais criadas pelo International Accounting Standards Board (IASB).

Nesse sentido, esta pesquisa tem por objetivo identificar como os profissionais contábeis do estado de Minas Gerais autoavaliam o seu conhecimento acerca do conteúdo e da aplicação dos pronunciamentos contábeis emitidos pelo Comitê de Pronunciamentos Contábeis (CPC).

Assim, gostaríamos de contar com sua participação para responder o presente questionário. Oportunamente, gostaríamos de destacar que a sua participação será somente para o preenchimento do questionário e, em nenhum momento, você ou a sua empresa serão identificados.

Você é livre para deixar de participar da pesquisa a qualquer momento sem nenhum prejuízo ou coação.

1)Dentre as categorias abaixo, indique aquela em que você se enquadra:

[ ]Contador com Cadastro Nacional de Auditores Independentes (CNAI)

[ ]Contador sem Cadastro Nacional de Auditores Independentes (CNAI)

[ ]Técnico em Contabilidade

[ ]Estudante

[ ]Professor

2)Por favor, indique a forma pela qual você exerce a profissão:

[ ]Contador de empresa

[ ]Empresário contábil

[ ]Funcionário público

[ ]Auditor/Consultor

[ ]Docente/Pesquisador

[ ]Outros

3)Como classificaria sua empresa?

[ ] Companhia aberta

[ ] Companhia fechada

[ ] Empresa limitada

[ ] Governo

[ ] Terceiro setor

[ ] Instituição de ensino/Outros

[ ] Prestadora de serviços contábeis/auditoria/consultoria

4)Qual é o seu cargo na companhia?

[ ] Diretor presidente

[ ] DIretor

[ ] Controller

[ ] Contador, auditor, gerente de tecnologia ou fiscal

[ ] Outros 
5)A lista abaixo contém os pronunciamentos técnicos emitidos pelo Comitê de Pronunciamento Contábeis, até (maio/2012), com vistas ao processo de convergência às Normas Internacionais de Contabilidade (IFRS). Por gentileza, atribua nota de "0" a "10" de forma a refletir o quanto você conhece sobre o conteúdo e a aplicação da cada daqueles pronunciamentos. Sendo, "0" para nenhum conhecimento e " 10 " para conhecimento total. Por favor, marque todos os pronunciamentos, pois, somente assim, conseguiremos traçar um perfil geral sobre o grau de atualização dos profissionais contadores do estado de Minas Gerais.

\begin{tabular}{|c|c|}
\hline \multirow{2}{*}{\multicolumn{2}{|c|}{$\begin{array}{c}\text { Pronunciamento } \\
\text { CPC 01 (R1) Redução ao Valor Recuperável de Ativos }\end{array}$}} \\
\hline & \\
\hline \multicolumn{2}{|l|}{ CPC 02 (R2) Efeitos das mud. nas tx. de câmbio e conv. de dem. contáb. } \\
\hline \multicolumn{2}{|l|}{ CPC 03 (R2) Demonstração dos Fluxos de Caixa } \\
\hline \multicolumn{2}{|l|}{ CPC 04 (R1) Ativo Intangível } \\
\hline \multicolumn{2}{|l|}{ CPC 05 (R1) Divulgação sobre Partes Relacionadas } \\
\hline \multicolumn{2}{|l|}{ CPC 06 (R1) Operações de Arrendamento Mercantil } \\
\hline \multicolumn{2}{|l|}{ CPC 07 (R1) Subvenção e Assistência Governamentais } \\
\hline \multicolumn{2}{|l|}{ CPC 08 (R1) Custos de Trans. e Prêmios na Emis.de Tít. e Vlr. Mobiliários } \\
\hline \multicolumn{2}{|l|}{ CPC 09 Demonstração do Valor Adicionado } \\
\hline \multicolumn{2}{|l|}{ CPC 10 (R1) Pagamento Baseado em Ações } \\
\hline \multicolumn{2}{|l|}{ CPC 11 Contratos de Seguro } \\
\hline \multicolumn{2}{|l|}{ CPC 12 Ajuste a Valor Presente } \\
\hline \multicolumn{2}{|l|}{ CPC 13 Adoção Inicial da Lei no ${ }^{\circ}$ 11.638/07 e da Med. Prov. no $.449 / 08$} \\
\hline \multicolumn{2}{|l|}{ CPC 15 (R1) Combinação de Negócios } \\
\hline \multicolumn{2}{|l|}{ CPC $16(\mathrm{R} 1)$ Estoques } \\
\hline \multicolumn{2}{|l|}{ CPC 17 Contratos de Construção } \\
\hline \multicolumn{2}{|l|}{ CPC 18 Investimento em Coligada e em Controlada } \\
\hline \multicolumn{2}{|l|}{ CPC 19 (R1) - Invest. em Empreendimento Controlado em Conjunto } \\
\hline \multicolumn{2}{|l|}{ CPC 20 (R1) Custos de Empréstimos } \\
\hline \multicolumn{2}{|l|}{ CPC 21 (R1) Demonstração Intermediária } \\
\hline \multicolumn{2}{|l|}{ CPC 22 Informações por Segmento } \\
\hline \multicolumn{2}{|l|}{ CPC 23 Políticas Contábeis, Mudança de Estimativa e Retific. de Erro } \\
\hline \multicolumn{2}{|l|}{ CPC 24 Evento Subsequente } \\
\hline \multicolumn{2}{|l|}{ CPC 25 Provisões, Passivos Contingentes e Ativos Contingentes } \\
\hline \multicolumn{2}{|l|}{ CPC 26 (R1) Apresentação das Demonstrações Contábeis } \\
\hline \multicolumn{2}{|l|}{ CPC 27 Ativo Imobilizado } \\
\hline \multicolumn{2}{|l|}{ CPC 28 Propriedade para Investimento } \\
\hline CPC 29 Ativo Biológico e Produto Agrícola & \\
\hline CPC 30 Receitas & \\
\hline CPC 31 Ativo Não Circ. Mantido para Venda e Oper. Descontinuada & \\
\hline CPC 32 Tributos sobre o Lucro & \\
\hline CPC 33 Benefícios a Empregados & \\
\hline CPC 35 (R1) Demonstrações Separadas & \\
\hline CPC 36 (R2) Demonstrações Consolidadas & \\
\hline CPC 37 (R1) Adoção Inicial das Normas Intern. de Contabilidade & \\
\hline CPC 38 - Instrumentos Financeiros: Reconhecimento e Mensuração & \\
\hline CPC 39 Instrumentos Financeiros: Apresentação & \\
\hline CPC 40 Instrumentos Financeiros: Evidenciação & \\
\hline CPC 41 Resultado por Ação & \\
\hline CPC 43 (R1) Adoção Inicial dos Pron. Téc. CPC 15 a 41 & \\
\hline CPC PME Contabilidade para Pequenas e Médias Empresas (R1) & \\
\hline
\end{tabular}

